\title{
Soil microbial biomass and community responses to experimental precipitation change: A meta-analysis
}

\author{
Shan $\mathrm{Xu}^{1}$, Weixin Geng ${ }^{2}$, Emma J. Sayer ${ }^{3,4}$, Guoyi Zhou ${ }^{5}$, Ping Zhou ${ }^{2}$, Chengshuai Liu ${ }^{1,6, *}$ \\ 1 Guangdong Key Laboratory of Integrated Agro-environmental Pollution Control and Management, Guangdong Institute of \\ Eco-environmental Science \& Technology, Guangzhou 510650, China \\ 2 Guangzhou Institute of Geography, Chinese Academy of Sciences, Guangzhou 510070, China \\ 3 Lancaster Environment Centre, Lancaster University, Lancaster, LA1 4YQ, UK \\ 4 Smithsonian Tropical Research Institute, Apartado 0843-03092, Balboa, Ancón, Panama \\ 5 Institute of Ecology, Nanjing University of Information Science \& Technology, Nanjing 210044, China \\ 6 State Key Laboratory of Environmental Geochemistry, Institute of Geochemistry, Chinese Academy of Sciences, Guiyang 550081, China
}

\section{ARTICLE I NFO}

Article history:

Received November 20, 2019

Revised April 5, 2020

Accepted April 9, 2020

\section{Keywords:}

Drought

Precipitation change

Microbial biomass

Microbial community

Treatment duration

\begin{abstract}
A B S T R A C T
The activity of soil microbes is strongly constrained by water availability. However, it is unclear how microbial activity responds to spatial and temporal changes in precipitation, particularly to long-term precipitation changes. To identify the spatiotemporal patterns of microbial responses to precipitation changes of differing durations, we conducted a meta-analysis of data from 95 field studies with drought treatments and 109 field studies with elevated precipitation treatments. Our results indicated that microbial biomass carbon (MBC) decreased by $17 \%$ under drought and increased by $18 \%$ under elevated precipitation. Across all studies, the phospholipid fatty acid (PLFA) biomarkers for fungi and bacteria decreased significantly under drought but increased under elevated precipitation. In addition, the negative effect of drought on MBC tended to be greater at sites with a high aridity index, but the effect of elevated precipitation on MBC did not differ among sites. More importantly, the responses of MBC, fungal and bacterial PLFA abundance did not vary with treatment duration under drought, but under elevated precipitation, they increased in the first five years of treatment and declined thereafter. These results are important for our prediction of microbial responses to long-term precipitation change, because they imply that microbes acclimate to long-term elevated precipitation.
\end{abstract}

(c) Higher Education Press 2020

\section{Introduction}

Global changes are having a substantial impact on the global hydrologic cycle via altered precipitation patterns and an increased frequency of extreme wet and dry events (Bintanja

\footnotetext{
* Corresponding author

E-mail address: liuchengshuai@vip.gyig.ac.cn (C. Liu)
}

and Selten, 2014; Schlaepfer et al., 2017; Bonan and Doney, 2018). Altered precipitation regimes have a profound influence on soil processes, most notably by directly affecting soil water content (Taylor et al., 2012; Brocca et al., 2014). Soil water content largely determines the percentage of oxygenfilled soil pores and the mobility of soil nutrients, and is therefore one of the major factors mediating the biomass, activity and composition of soil microbial communities (Schimel et al., 2007; Brockett et al., 2012; Manzoni et al., 
2012). Microbial responses to altered moisture regimes are highly variable (Borken and Matzner, 2009; Balser et al., 2010) because distinct microbial groups respond differently to variation in precipitation depending on their physiological tolerances and metabolic flexibility (Allison and Martiny, 2008; Manzoni et al., 2012; Zhao et al., 2017). Fungi are generally thought to be more tolerant to water stress than bacteria (Schimel et al., 1999; Zeglin et al., 2013), but a recent study suggests that long-term reductions in precipitation can have strong impacts on soil fungal communities (Sayer et al., 2017). Clarifying the microbial responses to altered precipitation patterns is important because soil microorganisms are key drivers of biogeochemical cycling and numerous important ecosystem processes such as decomposition and soil respiration. For example, as a result of greater fungal tolerance to stress, a higher ratio of fungi to bacteria ( $F: B$ ratio) in the soil could reduce the rates of organic matter turnover and soil respiration (Bailey et al., 2002; Kaisermann et al., 2015). In a paddy soil, ${ }^{13} \mathrm{CO}_{2}$ efflux was found to increase exponentially to a maximum value with an increase in the microbial biomass carbon to nitrogen ratio ( $\mathrm{C}: \mathrm{N}$ ratio) (Zhu et al., 2018). However, to fully evaluate the impact of altered precipitation, we must also consider how differences among sites and extant conditions influence the response of soil microbial communities to changes in soil water availability.

In experimental studies, the direction and magnitude of changes in soil microbial communities in response to different precipitation regimes depend on the extant humidity levels of the sites as well as the level and duration of treatments. Although gradient studies show that the biomass and abundance of soil microbes increase with increasing precipitation or soil water content (Bachar et al., 2010; Chen et al., 2015; Ma et al., 2015), the response of microbial communities to change is also shaped by their acclimation to the natural variation in soil water content among sites (Evans and Wallenstein, 2012; Wallenstein and Hall, 2012). For example, when soil microbes in drier regions are acclimated to periodic water stress, drought treatments may have little influence, whereas soil microbes acclimated to wetter regions may be more sensitive to drought treatments and less responsive to elevated precipitation (Evans and Wallenstein, 2012). However, the level of experimental drought or elevated precipitation also interacts with extant soil conditions, and the response of soil microbial communities to precipitation change will also depend upon the preexisting soil water content, because low soil water content can induce drought-stress, whereas high soil water content reduces the oxygen concentrations in the soil. Hence, particularly high or low levels of soil moisture also represent stressors, which can be alleviated or exacerbated by experimental treatments (Jensen et al., 2003; Bell et al., 2014), and as a result, previous studies with multiple treatment levels have found that indicators of microbial community biomass, abundance, and activity consistently increased at intermediate levels of supplemented rainfall
(30\% or $40 \%$ of mean annual precipitation; Huang et al., 2015; Zhao et al., 2016). To date, most experimental studies of microbial responses to altered precipitation patterns have focused on rainfall reduction treatments (Bouskill et al., 2013), and relatively fewer studies have examined the changes in microbial community composition in response to supplemented rainfall (Brzostek et al., 2012; Cregger et al., 2012). However, manipulative experiments with elevated precipitation are not only useful for studying water-limited systems, they can also provide critical insights into the impact of longterm global changes in precipitation regimes and patterns. Therefore, it is urgent to investigate how multiple levels of elevated precipitation affect soil microbial community depending on site conditions and experimental duration.

Last but not least, it remains unclear how soil microbes will acclimate to long-term changes in precipitation regimes, which represents a significant knowledge gap for predicting ecosystem responses to future climate change. Microbial communities can acclimate to new conditions ('resistance') or recover more rapidly after stress ('resilience'; sensu Griffiths et al., 2000; Griffiths and Philippot, 2012). Several long-term studies have demonstrated the increased resistance or resilience of microbial communities to altered precipitation treatments, for example, in a seven-year experiment in a desert grassland, there was no change in microbial biomass carbon during the first three years of supplemental rainfall treatments, but there were significant increases from the fourth year onwards (Bell et al., 2014). However, in a threeyear study in a semiarid grassland, the increased precipitation had an immediate positive effect on all the measured microbial parameters, which increased over time (Liu et al., 2009), whereas the microbial resilience to drying-rewetting cycles was altered by 18 years of summer drought treatments in a temperate heathland (de Nijs et al., 2018). Given the wide range of microbial responses to altered precipitation patterns and the potential influence of experimental site, treatment duration, and treatment level, it is important to identify general patterns in microbial community responses to both drought and elevated precipitation, which will help us predict changes in microbial community composition and activity.

Although Zhou et al. (2018) have previously presented the general patterns of soil microbe responses to precipitation changes, our meta-analysis goes further by investigating how the biomass and composition of microbial communities (represented by phospholipid fatty acids, PLFAs) responded to different levels of precipitation change. We further assessed how existing drought conditions influence microbial responses to precipitation change. More importantly, we assessed the sensitivity of microbial responses to the treatment duration of precipitation change by performing a meta-analysis of field-based manipulative experiments that reduce or elevate precipitation, respectively. We aimed to assess whether there were common patterns in the responses of soil microbial communities to experimentally altered precipitation across different climates with different 
treatment durations by testing the following hypotheses: (i) Microbial biomass and community composition will respond negatively to drought but positively to elevated precipitation, but the magnitude of the response will be influenced by the severity of treatments and the extant humidity levels among sites; (ii) Microbial physiology and community composition will acclimate to long-term precipitation change, and therefore, the magnitude of response of microbial biomass and community composition will decline with treatment duration.

\section{Materials and methods}

\subsection{Data collection}

We first conducted a comprehensive search of relevant peerreviewed articles and dissertations published from 2001 to 2018 in the Web of Science ${ }^{\circledR}$ and ProQuest databases using combinations of the following keywords: drought, decreased precipitation, elevated precipitation, increased precipitation, microbial, microbial biomass, microbial biomass carbon $(\mathrm{MBC})$, microbial biomass nitrogen (MBN), microbial community, phospholipid fatty acids (PLFAs), fungal PLFAs, bacterial PLFAs, Gram-positive (G + ) PLFAs, and Gram-negative ( $\left.G_{-}\right)$ PLFAs. We then cross-checked the references of the relevant articles to identify other relevant book chapters and peerreviewed reports. We extracted mean annual precipitation (MAP, mm), mean annual temperature (MAT, $\left.{ }^{\circ} \mathrm{C}\right)$, ecosystem type (forest, grassland, or shrubland), treatment level (\% $\mathrm{MAP}$ ), treatment duration (years), soil $\mathrm{pH}$, soil texture (\%sand, $\%$ silt, and \%clay), MBC, MBN, microbial biomass carbon to nitrogen ratio (MBC:MBN), total PLFAs, and individual functional groups and metrics defined by PLFA biomarkers in the surface $(<20 \mathrm{~cm})$ soil layer. When data from multiple years were given in the literature, we only used data from the most recent years to avoid temporal pseudo-replication (Koricheva and Gurevitch, 2014). Numerical values were extracted from graphically presented data by digitizing the figures using Engauge Digitizer (Free Software Foundation, Inc., Boston, USA). The experimental sites included in our study are shown in Fig. S1, which was generated by ggplot2 (Wickham, 2009). Unless otherwise stated, all data analyses were conducted using $\mathrm{R}$ version 3.4.2 (R Core Team, 2017) and the $R$ packages ggsn (Baquero, 2017) and legendMap (Gallic, 2016). Detailed information on the meta-analysis is provided in Supplement.

\subsection{Meta-analysis}

The data were analyzed following the methods of Hedges et al. (1999). The effect sizes for drought and elevated precipitation treatments were estimated for each observation using the natural log of the response ratio $(R R)$ : $\ln R R=\ln \left(\overline{X_{t}} / \overline{X_{c}}\right)$, where $\overline{X_{c}}$ is the control mean, and $\overline{X_{t}}$ is the treatment mean. Publication bias was estimated using a Gaussian function (Figs. S2 and S3 in Supplement), which was implemented in $\mathrm{R}$ version 3.3.3 ( $\mathrm{R}$ Core Team, 2017); the histogram of every $R R$ for the target variables exhibited a normal distribution, indicating the absence of publication bias. The average $R R$ was calculated using the mixed model of the meta-analytical software METAWIN (Sinauer Associates, Inc. Sunderland, USA). The variances of the mean effect sizes were calculated using resampling techniques (Adams et al., 1997). If the lower boundary of the $95 \%$ confidence interval (CI) of the $R R$ was $>1$, then the response was significantly positive at $P<0.05$. If the upper boundary of the $95 \% \mathrm{Cl}$ of the $R R$ was $<1$, then the response was significantly negative at $P<0.05$. A subgroup analysis was conducted for each parameter to identify the differences in the magnitude of the effects among ecosystem types. We present the results for individual ecosystem only where at least three observations were available in more than one subgroup. However, the results were considered valid when there were at least four observations (Fu et al., 2011). The total heterogeneity $\left(Q_{T}\right)$ was partitioned into within-group $\left(Q_{W}\right)$ and between-group $\left(Q_{B}\right)$ heterogeneities, whereby a significant $Q_{B}$ indicates a different $R R$ among groups (Hedges et al., 1999). Group means were considered significantly different if their $95 \% \mathrm{Cls}$ did not overlap.

\subsection{Aridity index}

To compare humidity levels among sites, we used the De Martonne aridity index (Al; de Martonne, 1926), which was calculated as follows for each site:

$$
\mathrm{AI}=\mathrm{MAP} /(\mathrm{MAT}+10)
$$

where MAP is the mean annual precipitation and MAT is the mean annual temperature. A lower aridity index value corresponds to more arid conditions, whereas a higher value corresponds to a more humid climate (Liu et al., 2016).

\subsection{Linear and nonlinear regression analyses}

The treatment levels for altered precipitation $(\mathrm{mm})$ were available in most of our data sources, and we expressed them relative to the mean annual precipitation (\%MAP) of the study site to facilitate comparison. To test whether treatment level affected the sensitivity of the microbial responses, we used linear regressions to examine the relationships between treatment levels and the effect sizes of changes in MBC. To determine whether there was a common pattern in the response of soil microbial biomass to drought or elevated precipitation treatments among sites with different humidity levels, we used linear regressions to examine the relationships between aridity indices and the effect sizes for changes in MBC. To assess the evidence for microbial acclimation to long-term changes in precipitation, we performed linear and nonlinear regressions (binomial) of the response ratios for each microbial parameter against treatment duration. Finally, the relationships between $\mathrm{MBC}$ and microbial respiration were assessed using linear regressions. 


\section{Results}

3.1 Responses of soil microbial communities to altered precipitation

Microbial biomass and community composition were strongly modified by changes in precipitation. Overall, under drought, MBC decreased by $17 \%(n=61)$ and total PLFAs decreased by $13 \%$ ( $n=18$; Fig. $1 \mathrm{~A})$, whereas under elevated precipitation, MBC increased by $18 \%(n=56)$ and total PLFAs increased by $22 \%$ ( $n=26$; Fig. 1B). The response of MBN to drought and elevated precipitation was similar to the response of $\mathrm{MBC}$, and hence there was no change in the microbial $\mathrm{C}: \mathrm{N}$ ratio in response to either treatment. There were distinct patterns between forest and grassland ecosystems in the effects of drought, whereby a negative effect of drought on MBC was observed in forests but not in grasslands (Fig. S4a). By contrast, microbial biomass and abundance responded similarly to elevated precipitation in both ecosystem types (Fig. S4b).

The effect of drought on MBC became increasingly negative with the increased severity of the drought treatment (Fig. $2 \mathrm{~A}, R^{2}=0.23, P=0.0005$ ), whereas there was no relationship between the response of $M B C$ and the level of elevated precipitation treatments (Fig. 2B).

Microbial functional groups were also strongly affected by altered precipitation. Across all studies, fungal and bacterial biomarkers declined significantly with drought and increased with elevated precipitation (Fig. 1A, B). Both $\mathrm{G}+$ and $\mathrm{G}_{-}$ bacterial biomarkers declined with drought but were unaffected by elevated precipitation, whereas the $F: B$ ratio

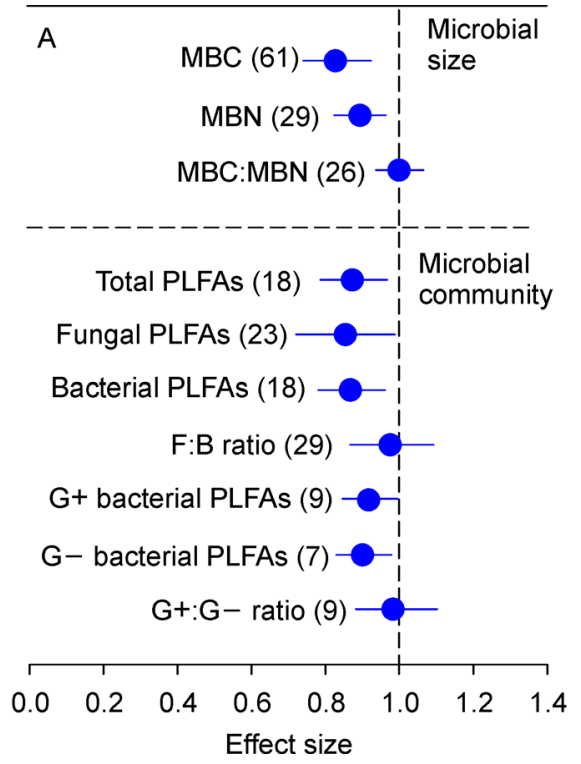

increased with elevated precipitation but was unaffected by drought (Fig. 1A, B). The ratio between $G+$ and $G-$ bacterial biomarkers was not affected by either drought or elevated precipitation treatments (Fig. 1A, B). The subgroup analysis of individual ecosystems revealed a strong increase in fungal biomarkers and in the $\mathrm{F}: \mathrm{B}$ ratio under elevated precipitation in grasslands but not in forests (Fig. S4b). There were insufficient data to evaluate the responses of $G+$ and $G-$ bacteria among ecosystems. However, the results showed that the responses of $\mathrm{G}$ - bacterial biomarkers to elevated precipitation differed significantly between acidic soils $(\mathrm{pH}<7)$ and alkaline soils $(\mathrm{pH}>7)$, with a decrease in $\mathrm{G}-$ bacterial biomarkers with elevated precipitation in alkaline soils (Fig. $\mathrm{S} 5 \mathrm{~b})$.

3.2 Spatiotemporal patterns of microbial communities under simulated precipitation changes

The negative effect of drought on MBC tended to be greater at sites with a high aridity index, but the relationship was weak (Fig. $3 \mathrm{~A}, R^{2}=0.09, P=0.03$ ), and the effect of elevated precipitation on MBC did not differ among sites regardless of their aridity index (Fig. 3B).

The duration of treatments included in our analysis ranged from 1 to 13 years. However, we found no evidence for an increasing impact of drought treatments over time; there was no relationship between the duration of drought treatments and the response of $\mathrm{MBC}$ (Fig. 4A). Accordingly, the responses of the different microbial functional groups did not change with the duration of the drought treatment. By contrast, the greatest response of $\mathrm{MBC}$ and fungal and bacterial PLFA

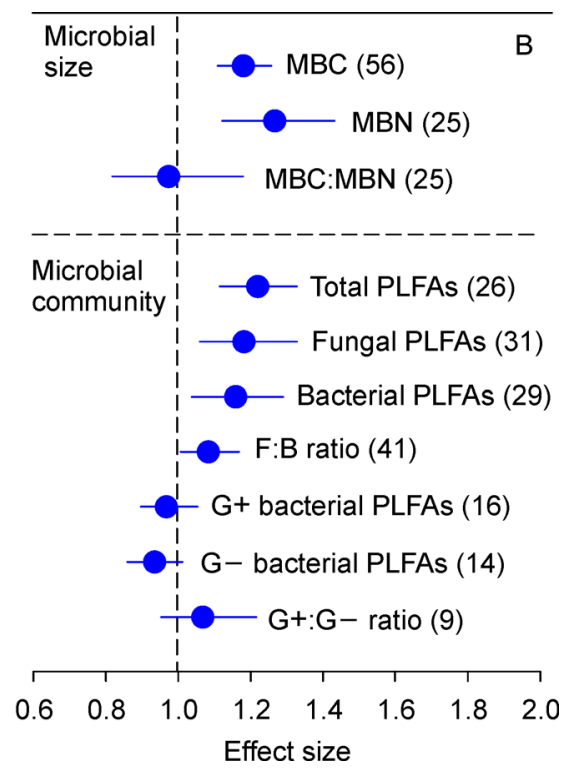

Fig. 1 Responses of microbial biomassand microbial communities to altered precipitation, i.e., (A) drought and (B) elevated precipitation; numbers in parentheses represent the number of observations for each parameter, and error bars represent $95 \%$ confidence intervals. Error bars overlapping the dashed vertical line indicate no effect relative to the controls, where MBC is microbial biomass carbon, MBN is microbial biomass nitrogen, PLFAs is phospholipid fatty acids, F:B is the ratio of fungal to bacterial PLFAs, $G+$ is Gram-positive bacteria, $G$ - is Gramnegative bacteria, $G+: G$ - is the ratio of Gram-positive bacterial to Gram-negative bacterial PLFAs. 

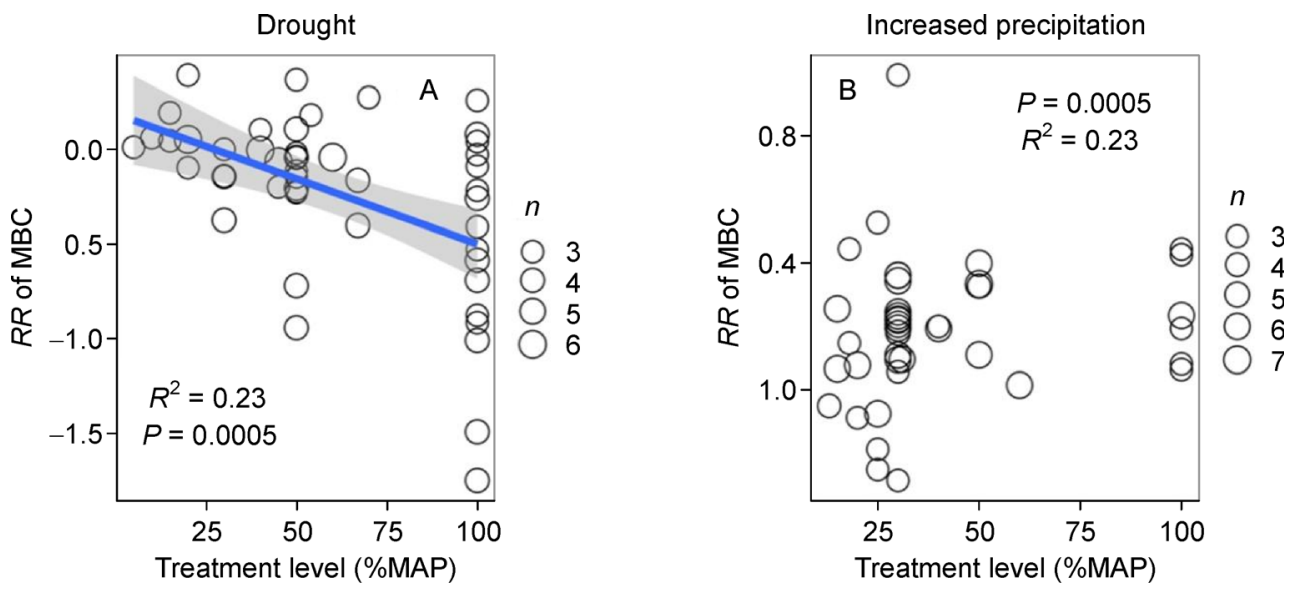

Fig. 2 Relationships between the level of drought or elevated precipitation treatments, expressed relative to the mean annual precipitation (\%MAP), and the response ratio of $\mathrm{MBC}$ under (A) drought and (B) elevated precipitation, where $R R$ is response ratio and other abbreviations follow the legend for Fig. 1. The symbol size $(n)$ represents the number of replicates in each study and the gray shading represents the confidence interval around the mean (line) when the relationship is significant at $P<0.05$.
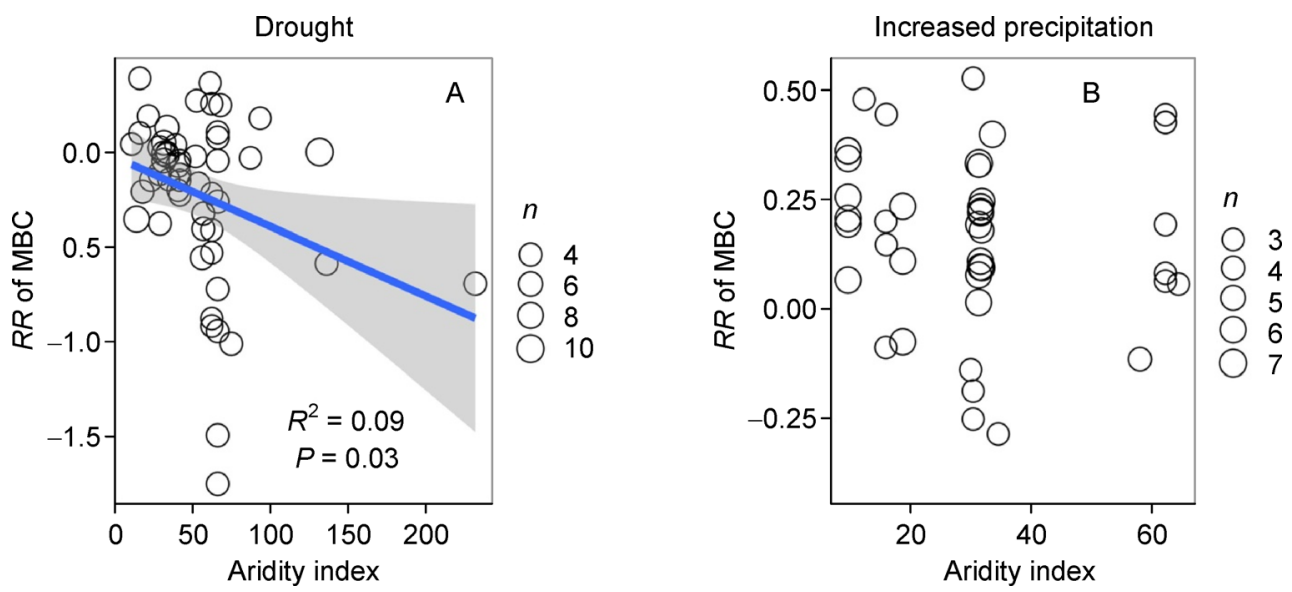

Fig. 3 Relationships between the aridity indices and the response ratio of $M B C$ under drought $(A)$ and under elevated precipitation (B). The abbreviations follow the legend for Fig. 2. The symbol size $(n)$ represents the number of replicates in each study and the gray shading represents the confidence interval around the mean (line) when the relationship is significant at $P<0.05$.
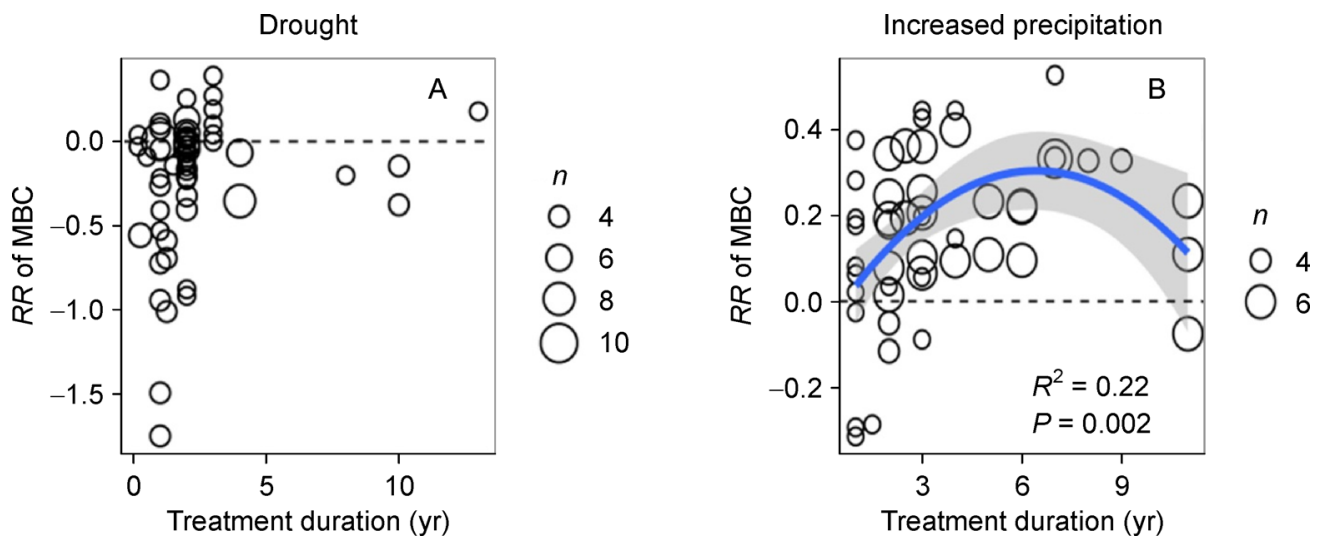

Fig. 4 Relationships between treatment duration (years) and the response ratio of MBC under (A) drought and under (B) elevated precipitation. The abbreviation yr indicates year; other abbreviations follow the legend for Fig. 2 . The symbol size $(n)$ represents the number of replicates in each study and the gray shading represents the confidence interval around the mean (line) when the relationship is significant at $P<0.05$. 
abundance to elevated precipitation occurred after five years of treatment and declined thereafter (Fig. 4B, Fig. 5E, F).

\subsection{Microbial respiration responses to altered precipitation}

Microbial respiration declined with drought and increased with elevated precipitation (Fig. 6A). The response of microbial respiration to elevated precipitation was strongly related to the response of MBC (Fig. $6 \mathrm{~B}, R^{2}=0.63, P=0.011$ ). There were insufficient studies to assess the relationships between the responses of microbial respiration or MBC and drought.

\section{Discussion}

Our global meta-analysis revealed general patterns in the responses of microbial biomass and community composition to experimentally modified precipitation across different ecosystems and climates. We showed that drought generally led to a decrease in microbial biomass and a decline in the abundance of key PLFA biomarkers, including fungal, bacterial, $\mathrm{G}+$ bacterial and $\mathrm{G}$ - bacterial PLFAs, but did not affect microbial stoichiometry (the ratio of microbial C:N) or change the ratios of key microbial functional groups. By

\section{Drought}
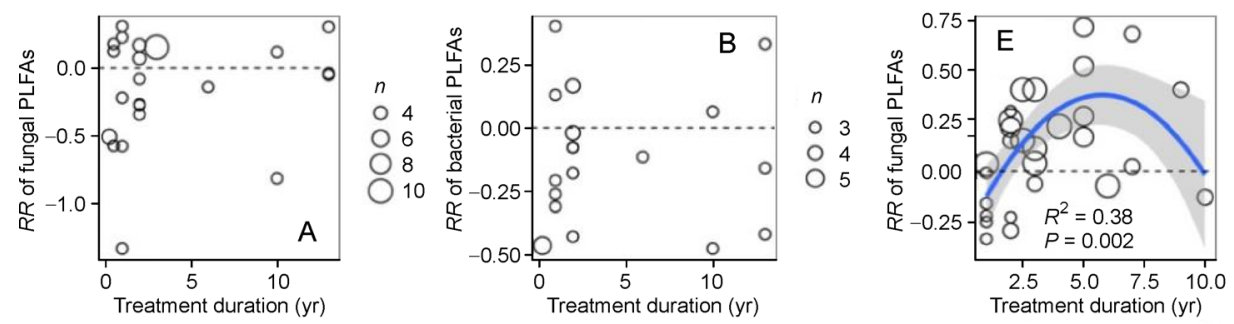

Increased precipitation
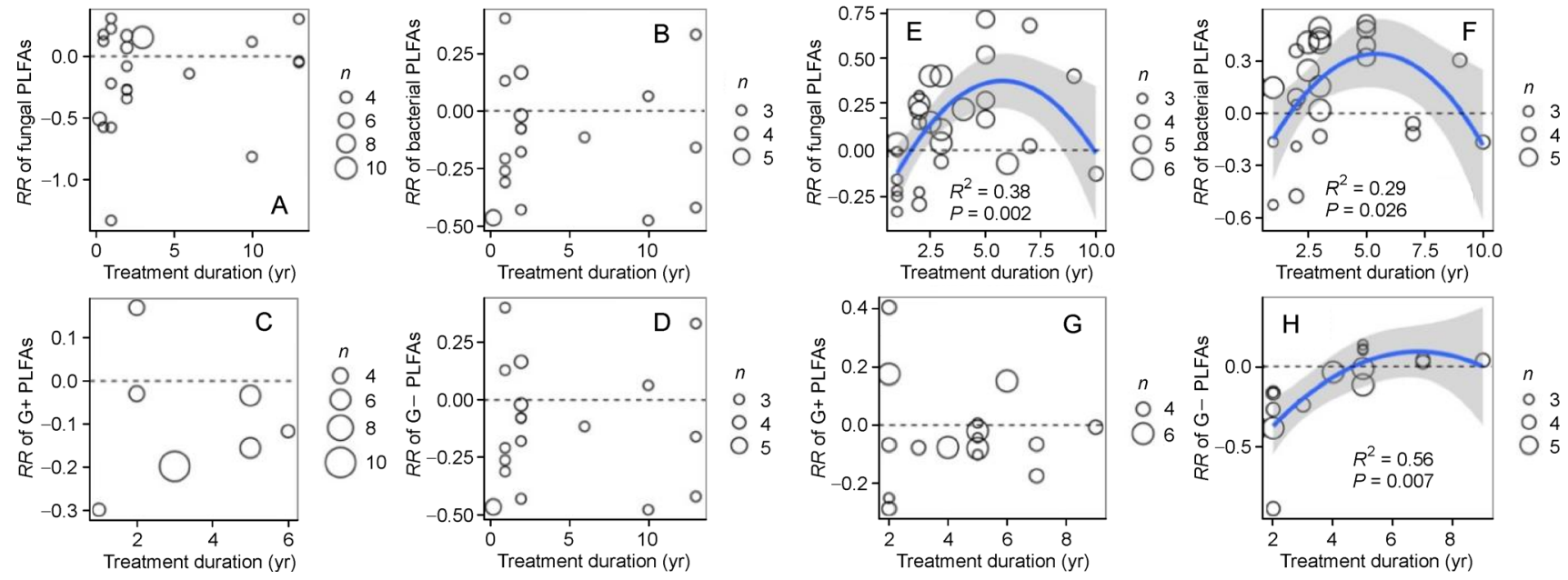

Fig. 5 Relationships between treatment duration in years $(\mathrm{yr})$ and the response ratios $(R R)$ of microbial functional groups for $(\mathrm{A})$ fungal PLFAs, (B) bacterial PLFAs, (C) G + PLFAs, (D) G - PLFAs under drought, and for (E) fungal PLFAs, (F) bacterial PLFAs, (G) G + PLFAs, (H) G- PLFAs under elevated precipitation; PLFAs are phospholipid fatty acids, $G+$ is Gram-positive bacteria and $G-$ is Gram-negative bacteria. The symbol size $(n)$ represents the number of replicates in each study and the gray shading represents the confidence interval around the mean (line) when the relationship is significant at $P<0.05$.
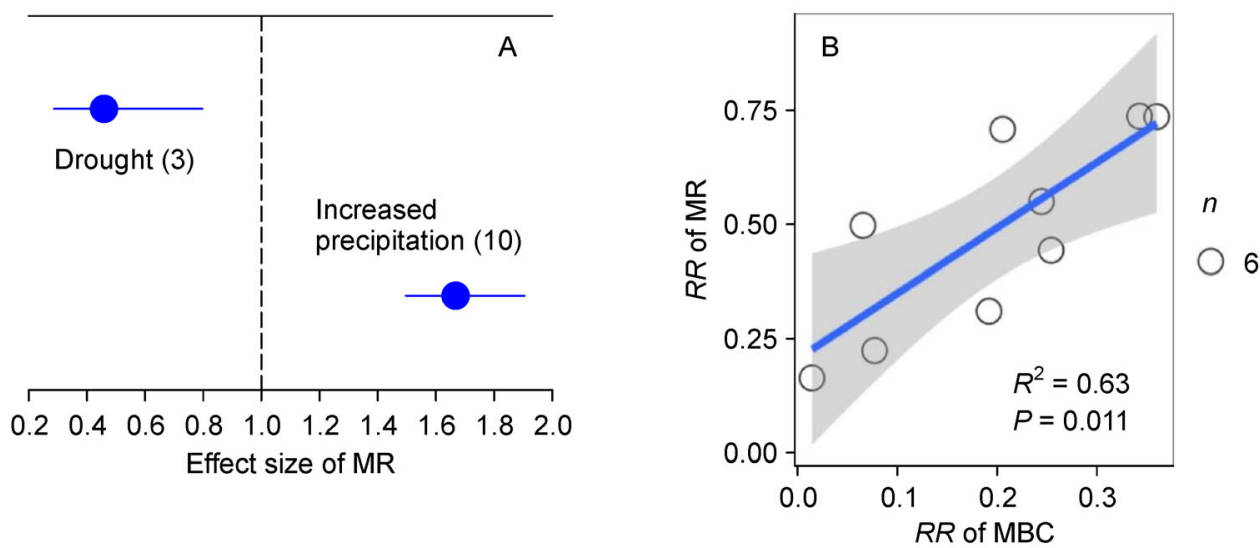

Fig. 6 The response of microbial respiration under drought and elevated precipitation $(A)$, and the relationship between microbial respiration and MBC (B). MR is microbial respiration; other abbreviations follow the legend for Fig. 1. The vertical line is drawn at an effect size of one (i.e., no effect), and the error bars that overlap the dashed line are not significant. The symbol size $(n)$ represents the number of replicates in each study and the gray shading represents the confidence interval around the mean (line) when the relationship is significant at $P<0.05$. 
contrast, elevated precipitation treatments led to increases in the microbial biomass and the abundance of PLFA biomarkers and a higher ratio of fungi to bacteria. Our results suggest that microbial communities can acclimate to long-term elevated precipitation but not to long-term drought. In contrast to the study of Zhou et al. (2018), we analyzed the responses of $\mathrm{MBC}$ and total PLFAs to the duration of precipitation change, which is very important for the prediction of soil microbial responses to long-term precipitation changes.

4.1 The effect of extant site humidity levels on the response of soil microbial communities

The biomass of soil microorganisms is often indicated by the concentrations of $\mathrm{MBC}$ and $\mathrm{MBN}$ in the soil, both of which decreased substantially under drought treatments and increased under elevated precipitation (Fig. 1A). This relationship not only reflects the importance of water availability for microbial growth but can also be partly attributed to variation in the availability of organic substrates (Figs. S7 and S8, Zhou et al., 2018; Wei et al., 2019). We also found that the sensitivity of $\mathrm{MBC}$ to drought increased with the treatment level (Fig. 2A). More importantly, the sensitivity of $M B C$ to drought was greater at relatively humid sites (Figs. $3 \mathrm{~A}$ and S10c), possibly because microbial communities at drier sites are more likely to acclimate to low water availability (Evans and Wallenstein, 2012). This difference in sensitivity was also reflected by the microbial responses in different ecosystems, as MBC and MBN declined significantly with drought in forests but not in grasslands (Fig. S4a), possibly because the aridity index of the forest sites $(\sim 60)$ in our study was significantly higher than that of the grassland sites ( 39; Fig. S6). However, the magnitude of the positive response of $\mathrm{MBC}$ to elevated precipitation was not related to treatment levels or aridity indices (Figs. 2B and 3B), which is consistent with the results of $\mathrm{MBC}$ responses to elevated precipitation between forest and grassland ecosystems (Fig. S4b).

We found no influence of drought on the $\mathrm{C}: \mathrm{N}$ ratio of the microbial biomass (Fig. 1A), which suggests that drought constrains microbial growth without altering microbial stoichiometry. This is noteworthy because the microbial $\mathrm{C}: \mathrm{N}$ ratio is generally considered a better indicator of changes in soil $\mathrm{C}$ and $\mathrm{N}$ cycling (Buchkowski et al., 2015) than microbial biomass, and our results suggest that microbial communities maintain a relatively stable $\mathrm{C}: \mathrm{N}$ ratio under drought conditions. The C:N ratio of fungi $(\sim 15)$ is higher than that of bacteria $(\sim 6$ Wallenstein et al., 2006), and given that fungi and bacteria are the dominant decomposers in soils (Schimel et al., 2007; Manzoni et al., 2012), the relatively stable microbial C:N ratio could also be related to the ratio of fungi to bacteria $(F: B)$ in the soil, which did not change under drought (Fig. 1A). However, the $F: B$ ratio increased under elevated precipitation without a concomitant change in the microbial $\mathrm{C}: \mathrm{N}$ ratio (Fig. 1B). Hence, the mechanisms underlying the stable microbial $\mathrm{C}: \mathrm{N}$ stoichiometry require further investigation.

Fungi and bacteria have distinct physiologies that underlie their responses to environmental stressors (Schimel et al., 2007; Manzoni et al., 2012). Fungi are generally considered drought-tolerant (Schimel et al., 2007; Strickland and Rousk, 2010; Manzoni et al., 2012), whereas bacteria may be more drought-sensitive (Holland and Coleman, 1987; Manzoni et al., 2012), and we therefore expected to see a greater decline in bacterial PLFAs under drought. However, both fungal and bacterial PLFAs declined significantly in drought treatments, and their responses were sufficiently similar that the $F: B$ ratio was not altered by drought (Fig. 1A). For example, a long-term manipulative precipitation experiment also showed that decreased precipitation did not change the $F: B$ ratio, although the original drier plots had higher $\mathrm{F}: \mathrm{B}$ ratios than the original wetter plots (Zeglin et al., 2013). The absence of change in the $F: B$ ratio suggests that the recalcitrance of soil $C$ may not be affected by drought, as soil $\mathrm{C}$ is expected to be more persistent when its storage is mediated by the fungal biomass and to be more labile when mediated by the bacterial biomass (Ho et al., 2017). Conversely, the increases in fungal and bacterial PLFA abundance as well as the $F: B$ ratio under elevated precipitation (Fig. 1B) are possibly related to greater availability of soil $C$ sources as suggested by the increase in dissolved organic carbon (DOC) under elevated precipitation (Fig. S7b). This is consistent with the results from $\mathrm{Ge}$ et al. (2017a), which found that shoot and root biomass increased with $\mathrm{N}$ fertilization as did fungal and bacterial biomarkers and $\mathrm{F}: \mathrm{B}$ ratios.

Different groups of bacteria also have distinct physiologies and life cycles that confer varying levels of stress-tolerance. Gram-positive bacteria, which have a thicker peptidoglycan layer in their cell walls, are generally considered to be more resistant to drought than Gram-negative bacteria (Schimel et al., 2007; Lennon et al., 2012; Manzoni et al., 2012). However, across all studies, both Gram-positive and Gram-negative bacterial PLFAs declined similarly under drought and did not change with elevated precipitation (Fig. 1A). It is possible that the low number of studies reporting data on individual taxonomic groups precludes the detection of a clear pattern across multiple ecosystems and climates (Fig. S4). Alternatively, the timing of measurements and the availability of substrates may play a more important role than the experimental treatment per se; Gram-negative bacteria predominantly use labile plant-derived $C$ as a substrate, whereas Gram-positive bacteria can use more recalcitrant $C$ sources derived from soil organic matter (Griffiths et al., 1999; Fierera et al., 2003; Kramer and Gleixner, 2006; Potthoff et al., 2006), and hence their resistance and resilience to drought treatments are also likely to differ as a result of changes in available resources. Although Gram-negative bacteria predominantly use labile plant-derived $\mathrm{C}$ as a substrate, they tend to favor acidic soils (Ge et al., 2017a), which explains why Gram-negative bacteria did not increase under elevated precipitation or with increased DOC concentration at higher soil pH (Fig. S7b). Indeed, when we calculated the effect sizes for soils with $\mathrm{pH}<7$ (acidic soils) or $\mathrm{pH}>7$ (alkaline soils), we found that the responses of $\mathrm{G}$ - bacterial biomarkers to 
elevated precipitation differed significantly between acidic soils $(\mathrm{pH}<7)$ and alkaline soils $(\mathrm{pH}>7)$, with a decrease in $\mathrm{G}$ - bacterial biomarkers in alkaline soils (Fig. S5b).

4.2 Evidence for microbial acclimation to long-term elevated precipitation but not to long-term drought treatments

Our meta-analysis demonstrated changes in the sensitivity of multiple microbial parameters to altered precipitation in field experiments lasting more than 10 years. We expected diminishing impacts of the treatments with increasing experimental duration as the microbial communities acclimated to altered precipitation patterns. However, we found no relationship between microbial responses to drought treatments and experimental duration (Fig. 4A), possibly because the majority of drought experiments had a duration of $<5$ years. However, it is noteworthy that the response of MBC was lower in the few drought experiments with a duration $>5$ years (Fig. 4A). By contrast, the responses of $M B C$ and fungal and bacterial PLFAs declined with the increasing duration of elevated precipitation treatments (Fig. 4B, Fig. 5E, F). Individual studies have observed changes in microbial biomass and community structure during continuous multi-year (5-6 years) treatments with increased precipitation and found that treatment duration affected the magnitude of the microbial response to elevated precipitation (Gutknecht et al., 2012; Bell et al., 2014). Together, these results suggest that drought stress has a large and immediate impact on soil microbial communities, but that microbial communities are better at acclimation to elevated precipitation over time. Several mechanisms could underlie the acclimation of microbial communities to increased precipitation, including the acclimation of individual microbial taxa (Allison et al., 2010; Crowther and Bradford, 2013), shifts in microbial community composition (Barcenas-Moreno et al., 2009; Treseder et al., 2016), and evolutionary adaptation of microbial populations (Romero-Olivares et al., 2015). These mechanisms are not mutually exclusive, and their relative influence may vary with season (Contosta et al., 2015), ecosystem, and time scale. The observed shifts in the fungal to bacterial ratio (Fig. 1B) could facilitate the acclimation of microbial communities to increased precipitation across sites, but further work is required to determine the mechanisms and the pace of microbial acclimation to climate changes to improve predictions of the long-term consequences of altered precipitation patterns for key soil microbial processes. Importantly, our results provide some evidence that the long-term impact of altered precipitation on soil microbial communities may be weaker than suggested by initial or short-term responses, and long-term experiments are therefore crucial for predicting future change.

The responses of decomposition processes to climate change depend on microbial community composition (Glassman et al., 2018), and microbial respiration during decomposition is an important component of soil $\mathrm{CO}_{2}$ efflux. Changes in precipitation can influence microbial respiration via the impact on microbial biomass and community composi- tion (Huang et al., 2015; Ren et al., 2018). Our results showed that the extent of the changes in microbial respiration under elevated precipitation (Fig. 6A) was strongly related to the sensitivity of the microbial biomass (Fig. 6B). Although there are currently insufficient data to predict whether microbial respiration will acclimate to long-term variation in precipitation, the relationship between MBC and microbial respiration suggests that the response in respiration will most likely parallel the observed decline in the response of MBC after 5 years of elevated precipitation (Fig. 6B). The lack of data on microbial activity in response to drought represents a significant knowledge gap in our understanding of the impact of altered precipitation patterns on ecosystem functioning.

\section{Conclusions}

Given the importance of microbial processes in soil functioning and plant productivity, our meta-analysis informs future global change research by identifying the spatiotemporal patterns in the response of microbial biomass and community composition to altered precipitation regimes. Our results suggest that microbial communities can acclimate to longterm elevated precipitation but not to long-term drought. In contrast to the study by Zhou et al. (2018), we analyzed the responses of $\mathrm{MBC}$ and PLFAs to experimental duration, which is important for predicting the responses of soil microbes to long-term precipitation changes. However, we still lack longterm experiments ( $>10$ years duration) that focus on soil microbial activity and function, particularly in response to drought. Detailed studies on soil microbial community composition, specific functional groups and key microbial processes are required to improve predictions of future ecosystem functioning under altered precipitation regimes.

\section{Acknowledgments}

This study was financially supported by the Key Research Program of the Chinese Academy of Sciences (QYZDJ-SSWDQC003), the National Natural Science Foundation of China (31901135 and U1612442), Guangdong Natural Science Foundation (2020A1515011257), the Science and Technology Foundation of Guangdong, China (2017BT01Z176), and the General Development Agreements' (GDAS) Project of Science and Technology Development (2019GDASYL-0301002). EJS was supported by funding from the European Research Council under the European Union's Seventh Framework Programme (FP/ 2007-2013), ERC Grant Agreement No. 307888.

\section{Author contributions}

SX and $C L$ designed this study. SX conducted the literature searches, and SX and WXG collected the data. SX analyzed the data and wrote the paper. EJS, GZ and PZ contributed to data interpretation and commented on the details of the manuscript drafts. 


\section{Conflict of interest}

The authors declare that they have no conflict of interest.

\section{Data availability}

The data set of the peer-reviewed publication will be accessible after acceptance.

\section{Electronic supplementary material}

Supplementary material is available in the online version of this article at http://dx.doi.org/10.1007/s42832-020-0033-7 and is accessible for authorized users.

\section{References}

Adams, D.C., Gurevitch, J., Rosenberg, M.S., 1997. Resampling tests for meta-analysis of ecological data. Ecology 78, 1277-1283.

Allison, S.D., Martiny, J.B.H., 2008. Resistance, resilience, and redundancy in microbial communities. Proceedings of the National Academy of Sciences of the United States of America 105, 11512 11519.

Allison, S.D., Wallenstein, M.D., Bradford, M.A., 2010. Soil-carbon response to warming dependent onmicrobial physiology. Nature Geoscience 3, 336-340.

Bachar, A., Al-Ashhab, A., Soares, M., Sklarz, M.Y., Angel, R., Ungar, E.D., Gillor, O., 2010. Soil microbial abundance and diversity along a low precipitation gradient. Microbial Ecology 60, 453-461.

Bailey, V.L., Smith, J.L., Bolton, H. Jr, 2002. Fungal-to-bacterial ratios in soils investigated for enhanced $C$ sequestration. Soil Biology \& Biochemistry 34, 997-1007.

Balser, T.C., Gutknecht, J.L.M., Liang, C., 2010. How Will Climate Change Impact Soil Microbial Communities? In: Dixon, G.R. Tilston, E.L., eds. Soil Microbiology and Sustainable Crop Production. Springer, Dordrecht, pp.373-397.

Baquero, O.S., 2017. ggsn: North Symbols and Scale Bars for Maps Created with 'ggplot2' or 'ggmap'. Available at https://CRAN.Rproject.org/package $=$ ggsn.

Barcenas-Moreno, G., Gomez-Brandon, M., Rousk, J., Baath, E., 2009. Adaptation of soil microbial communities to temperature: comparison of fungi and bacteria in a laboratory experiment. Global Change Biology 15, 2950-2957.

Bell, C.W., Tissue, D.T., Loik, M.E., Wallenstein, M.D., AcostaMartinez, V., Erickson, R.A., Zak, J.C., 2014. Soil microbial and nutrient responses to 7 years of seasonally altered precipitation in a Chihuahuan Desert grassland. Global Change Biology 20, 1657 1673.

Bintanja, R., Selten, F.M., 2014. Future increases in Arctic precipitation linked to local evaporation and sea-ice retreat. Nature 509, $479-482$.

Bonan, G.B., Doney, S.C., 2018. Climate, ecosystems, and planetary futures: The challenge to predict life in Earth system models. Science 359, 533

Borken, W., Matzner, E., 2009. Reappraisal of drying and wetting effects on $\mathrm{C}$ and $\mathrm{N}$ mineralization and fluxes in soils. Global Change Biology 15, 808-824.

Bouskill, N.J., Lim, H.C., Borglin, S., Salve, R., Wood, T.E., Silver, W. L., Brodie, E.L., 2013. Pre-exposure to drought increases the resistance of tropical forest soil bacterial communities to extended drought. ISME Journal 7, 384-394.

Brocca, L.L., Ciabatta, C.M., Moramarco, T., Hahn, S., Hasenauer, S., Kidd, R., Dorigo, W., Wagner, W., Levizzani V., 2014. Soil as a natural rain gauge: Estimating global rainfall from satellite soil moisture data. Journal of Geophysical Research, D, Atmospheres 119, 5128-5141.

Brockett, B.F.T., Prescott, C.E., Grayston, S.J., 2012. Soil moisture is the major factor influencing microbial community structure and enzyme activities across seven biogeoclimatic zones in western Canada. Soil Biology \& Biochemistry 44, 9-20.

Brzostek, E.R., Blair, J.M., Dukes, J.S., Frey, S.D., Hobbie, S.E., Melillo, J.M., Mitchell, R.J., Pendall, E., Reich, P.B., Shaver, G.R., Stefanski, A., Tjoelker, M.G., Finzi, A.C., 2012. The effect of experimental warming and precipitation change on proteolytic enzyme activity: positive feedbacks to nitrogen availability are not universal. Global Change Biology 18, 2617-2625.

Buchkowski, R.W., Schmitz, O.J., Bradford, M.A., 2015. Microbial stoichiometry overrides biomass as a regulator of soil carbon and nitrogen cycling. Ecology 96, 1139-1149.

Chen, D., Mi, J., Chu, P., Cheng, J., Zhang, L., Pan, Q., Xie, Y., Bai, Y., 2015. Patterns and drivers of soil microbial communities along a precipitation gradient on the Mongolian Plateau. Landscape Ecology 30, 1669-1682.

Contosta, A.R., Frey, S.D., Cooper, A.B., 2015. Soil microbial communities vary as much over time as with chronic warming and nitrogen additions. Soil Biology \& Biochemistry 88, 19-24.

Cregger, M.A., Schadt, C.W., McDowell, N.G., Pockman, W.T., Classena, A.T., 2012. Response of the soil microbial community to changes in precipitation in a semiarid ecosystem. Applied and Environmental Microbiology 78, 8587-8594.

Crowther, T.W., Bradford, M.A., 2013. Thermal acclimation in widespread heterotrophic soil microbes. Ecology Letters 16, 469-477.

de Martonne, E., 1926. Une nouvelle fanction climatologique: l'indice d'aridite. Meteorologie (Paris) 2, 449-458.

de Nijs, E.A., Hicks, L.C., Leizeaga, A., Tietema, A., Rousk, J., 2018. Soil microbial moisture dependences and responses to dryingrewetting: The legacy of 18 years drought. Global Change Biology 25, 1005-1015

Evans, S.E., Wallenstein, M.D., 2012. Soil microbial community response to drying and rewetting stress: does historical precipitation regime matter? Biogeochemistry 109, 101-116.

Fierera, N., Schimela, J.P., Holden, P.A., 2003. Variations in microbial community composition through two soil depth profiles. Soil Biology \& Biochemistry 35, 167-176.

Fu, R., Gartlehner, G., Grant, M., Shamliyan, T., Sedrakyan, A., Wilt, T. J., Griffith, L., Oremus, M., Raina, P., Ismaila, A., Santaguida, P., Lau, J., Trikalinos, T.A., 2011. Conducting quantitative synthesis when comparing medical interventions: $A H R Q$ and the Effective Health Care Program. Journal of Clinical Epidemiology 64, 11871197.

Gallic, E., 2016. legendMap: North arrow and scale bar for ggplot2 
graphics. R package version 1.0.

Ge, T., Li, B., Zhu, Z., Hu, Y., Yuan, H., Dorodnikov, M., Jones, D.L., Wu, J., Kuzyakov, Y., 2017. Rice rhizodeposition and its utilization by microbial groups depends on $\mathrm{N}$ fertilization. Biology and Fertility of Soils $53,37-48$.

Glassman, S.I., Weihe, C., Li, J., Albright, M.B.N., Looby,C.I., Martiny, A.C., Treseder, K.K., Allison, S.D., Martiny, J.B.H., 2018. Decomposition responses to climate depend on microbial community composition. Proceedings of the National Academy of Sciences of the United States of America 115: 11994-11999.

Griffiths, B.S., Bonkowski, M., Dobson, G., Caul, S., 1999. Changes in soil microbial community structure in the presence of microbialfeeding nematodes and protozoa. Pedobiologia 43, 297-304.

Griffiths, B.S., Philippot, L., 2012. Insights into the resistance and resilience of the soil microbial community. FEMS Microbiology Reviews 37, 112-129.

Griffiths, R.I., Whiteley, A.S., O’Donnell, A.G., Bailey, M.J., 2000. Rapid method for coextraction of DNA and RNA from natural environments for analysis of ribosomal DNA and rRNA-Based microbial community composition. Applied and Environmental Microbiology 12, 5488-5491.

Gutknecht, J.L.M., Field, C.B., Balser, T.C., 2012. Microbial communities and their responses to simulated global change fluctuate greatly over multiple years. Global Change Biology 18, 22562269.

Hedges, L.V., Gurevitch, J., Curtis, P.S., 1999. The meta-analysis of response ratios in experimental ecology. Ecology 80, 1150-1156.

Ho, A., Lonardo, D.P.D., Bodelier, P.L.E., 2017. Revisiting life strategy concepts in environmental microbial ecology. FEMS Microbiology Ecology 93, fix006.

Holland, E.A., Coleman, D.C., 1987. Litter placement effects on microbial and organic matter dynamics in an agroecosystem. Ecology 68, 425-433.

Huang, G., Li, Y., Su, Y.G., 2015. Effects of increasing precipitation on soil microbial community composition and soil respiration in a temperate desert, Northwestern China. Soil Biology \& Biochemistry $83,52-56$.

Jensen, K.D., Beier, C., Michelsen, A., Emmett, B.A., 2003. Effects of experimental drought on microbial processes in two temperate heathlands at contrasting water conditions. Applied Soil Ecology 24, 165-176.

Kaisermann, A., Maron, P.A., Beaumelle, L., Lata, J.C., 2015. Fungal communities are more sensitive indicators to non-extreme soil moisture variations than bacterial communities. Applied Soil Ecology 86, 158-164.

Koricheva, J., Gurevitch, J., 2014. Uses and misuses of meta-analysis in plant ecology. Journal of Ecology 102, 828-844.

Kramer, C., Gleixner, G., 2006. Variable use of plant- and soil-derived carbon by microorganisms in agricultural soils. Soil Biology \& Biochemistry 38, 3267-3278.

Lennon, J.T., Aanderud, Z.T., Lehmkuhl, B.K., Schoolmaster, J.D.R. $\mathrm{Jr}, 2012$. Mapping the niche space of soil microorganisms using taxonomy and traits. Ecology 93, 1867-1879.

Liu, L., Wang, X., Lajeunesse, M.J., Miao, G., Piao, S., Wan, S., Wu, Y., Wang, Z., Yang, S., Li, P., Deng, M., 2016. A cross-biome synthesis of soil respiration and its determinants under simulated precipitation changes. Global Change Biology 22, 1394-1405.

Liu, W., Zhang, Z., Wan, S., 2009. Predominant role of water in regulating soil and microbial respiration and their responses to climate change in a semiarid grassland. Global Change Biology 15, 184-195.

Ma, L., Guo, C., Lü, X., Yuan, S., Wang, R., 2015. Soil moisture and land use are major determinants of soil microbial community composition and biomass at a regional scale in northeastern China. Biogeosciences 12, 2585-2596.

Manzoni, S., Schimel, J.P., Porporato, A., 2012. Responses of soil microbial communities to water stress: results from a metaanalysis. Ecology 93, 930-938.

Potthoff, M., Steenwerth, K.L., Jackson, L.E., Drenovsky, R.E., Scow, K.M., Joergensen, R.G., 2006. Soil microbial community composition as affected by restoration practices in California grassland. Soil Biology \& Biochemistry 38, 1851-1860.

Ren, C., Chen, J., Lu, X., Doughty, R., Zhao, F., Zhong, Z., Han, X., Yang, G., Feng, Y., Ren, G., 2018. Responses of soil total microbial biomass and community compositions to rainfall reductions. Soil Biology \& Biochemistry 116, 4-10.

Romero-Olivares, A.L., Taylor, J.W., Treseder, K.K., 2015. Neurospora discreta as a model to assess adaptation of soil fungi to warming. BMC Evolutionary Biology 15, 198.

Sayer, E.J., Oliver, A.E., Fridley, J.D., Askew, A.P., Mills, R.T.E., Grime, J.P., 2017. Links between soil microbial communities and plant traits in a species-rich grassland under long-term climate change. Ecology and Evolution 7, 855-862.

Schimel, J., Balser, T.C., Wallenstein, M., 2007. Microbial stressresponse physiology and its implications for ecosystem function. Ecology 88, 1386-1394.

Schimel, J.P., Gulledge, J.M., Clein-Curley, J.S., Lindstrom, J.E., Braddock, J.F., 1999. Moisture effects on microbial activity and community structure in decomposing birch litter in the Alaskan taiga. Soil Biology \& Biochemistry 31, 831-838.

Schlaepfer, D.R., Bradford, J.B., Lauenroth, W.K., Munson, S.M., Tietjen, B., Hall, S.A., Wilson, S.D., Duniway, M.C., Jia, G., Pyke, D.A., Lkhagva, A., Jamiyansharav, K., 2017. Climate change reduces extent of temperate drylands and intensifies drought in deep soils. Nature Communications 8, 14196.

Strickland, M.S., Rousk, J., 2010. Considering fungal: bacterial dominance in soils-methods, controls, and ecosystem implications. Soil Biology \& Biochemistry 42, 1385-1395.

Taylor, C.M., de Jeu, R.A.M., Guichard, F., Harris, P.P., Dorigo, W.A., 2012. Afternoon rain more likely over drier soils. Nature 489, 423426.

Treseder, K.K., Marusenko, Y., Romero-olivares, A.L., Maltz, M.R., 2016. Experimental warming alters potential function of the fungal community in boreal forest. Global Change Biology 22, 33953404.

Wallenstein, M.D., Hall, E.K., 2012. A trait-based framework for predicting when and where microbial adaptation to climate change will affect ecosystem functioning. Biogeochemistry 109, 35-47.

Wallenstein, M.D., McNulty, S., Fernandez, I.J., Boggs, J., Schlesinger, W.H., 2006. Nitrogen fertilization decreases forest soil fungal and bacterial biomass in three long-term experiments. Forest Ecology and Management 222, 459-468. 
Wei, L., Razavi, B.S., Wang, W., Zhu, Z., Liu, S., Wu, J., Kuzyakov, Y. $\mathrm{Ge}, \mathrm{T}$., 2019. Labile carbon matters more than temperature for enzyme activity in paddy soil. Soil Biology \& Biochemistry 135 , 134-143.

Wickham, H. 2009. ggplot2: Elegant Graphics for Data Analysis. Springer-Verlag New York.

Zeglin, L.H., Bottomley, P.J., Jumpponen, A., Rice, C.W., Arango, M., Lindsley, A., McGowan, A., Mfombep, P., Myrold, D.D., 2013. Altered precipitation regime affects the function and composition of soil microbial communities on multiple time scales. Ecology 94 , 2334-2345.

Zhao, C., Miao, Y., Yu, C., Zhu, L., Wang, F., Jiang, L., Hui, D., Wan, S., 2016. Soil microbial community composition and respiration along an experimental precipitation gradient in a semiarid steppe. Scientific Reports 6, 24317.

Zhao, Q., Jian, S., Nunan, N., Maestre, F.T., Tedersoo, L., He, J., Wei, H., Tan, X., Shen, W., 2017. Altered precipitation seasonality impacts the dominant fungal but rare bacterial taxa in subtropical forest soils. Biology and Fertility of Soils 53, 231-245.

Zhou, Z., Wang, C., Luo, Y., 2018. Response of soil microbial communities to altered precipitation: A global synthesis. Global Ecology and Biogeography 27, 1121-1136.

Zhu, Z., Ge, T., Luo, Y., Liu, S., Xu, X., Tong, C., Shibistova, O., Guggenberger, G., Wu, J., 2018. Microbial stoichiometric flexibility regulates rice straw mineralization and its priming effect in paddy soil. Soil Biology \& Biochemistry 121, 67-76 